\title{
Blackstart of An Induction Motor in An Autonomous Microgrid
}

\author{
Ahmad Tazay, Zhixin Miao, Senior Member, IEEE, and Lingling Fan, Senior Member, IEEE
}

\begin{abstract}
Starting of large induction motors may produce voltage dip in a weak microgrid because of high current and reactive power demand in transient period. This paper develops a solution for black start issue of an Induction Motor (IM) using Voltage-Sourced Converter (VSC) interfaced source in an autonomous microgrid. This paper provides procedures and techniques for controlling the VSC. First, a dynamic model of a microgrid is analyzed to provide a designing criteria of VSC's controller. Vector control is implemented to control the voltage and frequency of the VSC at autonomous mode. Second, the issue of black start of IM is investigated and analyzed. A proposed technique is presented in order to solve the overcurrent and voltage dip due to black start of IM. Finally, a microgrid is modeled and simulated in PSCAD/EMTDC to validate the proposed technique on black start.
\end{abstract}

Index Terms-Microgrid, Autonomous Mode, Vector Control, Voltage-Sourced Converter (VSC), V/F Control, Black Start, Inrush Current, Soft Start.

\section{INTRODUCTION}

Power electronics play an important role in converting DC power into AC power from distributed generators (DGs) to controllable loads. VSC is one of the commonly used power electronic devices that are recently implemented in controlling a microgrid due to several advantages such as independent control of voltage and frequency, possibility to be connected to weak ac grid and ability to mitigate the negative effect of disturbance [1]-[3].

Active loads such as induction motors occupy almost $50 \%$ of all loads in real applications [4]. The major problem of operating large IM is voltage dip in case of a weak system.

Three important elements have to be considered in the case of blackstart of IM that involve starting current, reactive power consumption, and voltage dip. First, the high consuming current during start-up condition is the main reason of blackstart. This current may absorb almost five to ten times the rated current. Second, the motor consumes high reactive power during the start-up condition because of high starting current. Finally, high starting current could generate voltage dip which will affect the IM torque since the torque is promotional to the square value of the voltage. It also may affect other loads and the system's stability. According to IEEE, the acceptable range of voltage dip during starting motors is between $80 \%$ to $90 \%$ of the full rated voltage [4]. Voltage dip is the major concern in starting motors in case of weak autonomous microgrid.

Different methods have been used to reduce the negative

L. Fan, Z. L. Miao, and A. are with the Department of Electrical Engineering, University of South Florida, Tampa, FL 33620 USA (e-mail: linglingfan@ usf.edu; zmiao@usf.edu; ahmadtazay@mail.usf.edu). effect of starting large motor [5]. In case of small motors, Direct-On-Line (DOL) method is used because of low consuming reactive power and starting current. In case of large induction motors, reducing applied voltage or providing higher reactive power is needed to avoid voltage dip during starting period of the motor [4]-[6].

In this paper, the strategy of reducing applied voltage during IM startup will be applied in an autonomous microgrid. An IM will be served by a VSC interfaced voltage source during startup. Though VSC control, blackstart of the IM without overcorrect will be realized.

The rest of the paper is organized as follows. Section II describes the system design and control concept of VSC based autonomous microgrid. It also develops mathematical model and tuning techniques of the transfer function equations. Section III studies and analyzes the behavior of the system when IM connected to a weak microgrid. It also provides a proposed technique to control of IM during start-up condition. Section IV tests the performance of the designing controller and proposed technique by using PSCAD/EMTDC software simulation. Section $\mathrm{V}$ concludes and summarizes the main points of the paper.

\section{V/F CONTROL OF VSC IN AN AUTONOMOUS MICROGRID}

\section{A. V/F Plant Model}

Vector control methodology is used to control voltage and frequency of VSC [7]-[9]. A schematic controller design of VSC at an autonomous microgrid is shown in Fig. 1. The concept of vector control depends on transferring symmetrical signals from three-phase time domain into two-phase rotating synchronous reference frame. The direct transformation of three-phase sinusoidal signal into two-phase constant signal is calculated by using Park's transformation [10].

The dynamic equations of the system in Fig. 1 are analyzed to find the states and controlled variables of VSC. Two main components need to be controlled which are output current and voltage of VSC. KVL and KCL are applied to find the dynamic equations of the inner current loop and outer voltage loop, respectively as follows:

$$
\begin{aligned}
L \frac{d i_{L_{\mathrm{abc}}}}{d t} & =-R i_{\mathrm{abc}}+V_{s_{\mathrm{abc}}}-E_{\mathrm{pcc}_{\mathrm{abc}}} \\
C \frac{d V_{C_{\mathrm{abc}}}}{d t} & =i_{\mathrm{abc}}-i_{\mathrm{labc}}
\end{aligned}
$$




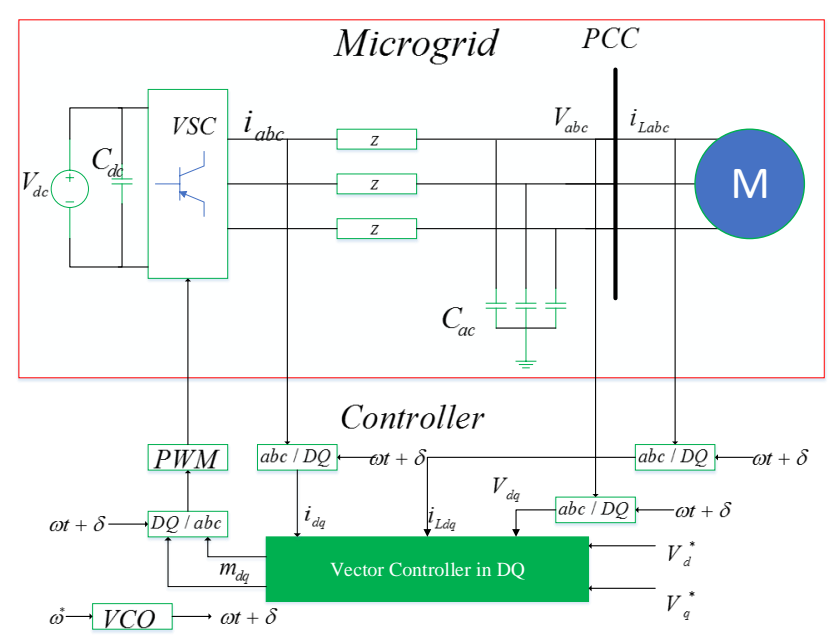

Fig. 1. General scheme of a VSC using vector control.

The current and voltage equations in Eqns. (1) and (2) are transferred into DQ reference frame as follows:

$$
\begin{aligned}
C \frac{d V_{s d}}{d t} & =C \omega V_{s q}+i_{d}-i_{l d} \\
C \frac{d V_{s q}}{d t} & =-C \omega V_{s d}+i_{q}-i_{l q} \\
L \frac{d i_{d}}{d t} & =-R i_{d}+L \omega(t) i_{q}+V_{s d} \\
L \frac{d i_{q}}{d t} & =-R i_{q}-L \omega(t) i_{d}+V_{s q}
\end{aligned}
$$

Controlling the inner and outer loops is applied in Laplacedomain. The current equations in Laplace-domain are shown as:

$$
\begin{aligned}
i_{d} & =\frac{1}{L s+R} u_{i d}(s) \\
i_{q} & =\frac{1}{L s+R} u_{i q}(s)
\end{aligned}
$$

Where

$$
\begin{aligned}
& u_{i d}(s)=-L \omega i_{q}(s)+V_{s d}(s) \\
& u_{i q}(s)=+L \omega i_{d}(s)+V_{s q}(s)
\end{aligned}
$$

The inner current control design is shown in Fig. 2 where $K_{i d}$ and $K_{i q}$ are the PI-compensators in DQ reference frame.

The dynamic equations of the voltage controller in Laplace-

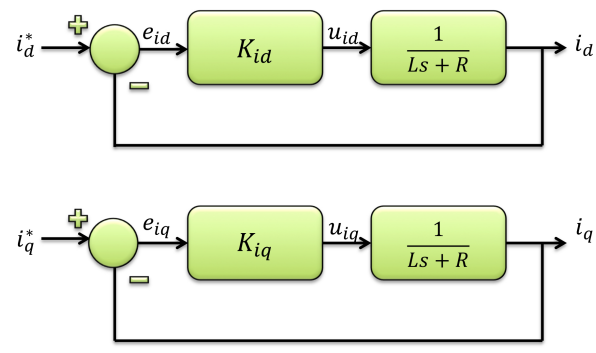

Fig. 2. Simplified control block diagram of the inner current loop. domain are obtained as:

$$
\begin{aligned}
V_{s d}(s) & =\frac{1}{C s} u_{v d}(s) G_{i}(s) \\
V_{s q}(s) & =\frac{1}{C s} u_{v q}(s) G_{i}(s)
\end{aligned}
$$

where

$$
\begin{array}{r}
u_{v d}=-C \omega V_{C q}+i_{l d} \\
u_{v q}=+C \omega V_{C d}+i_{l q} \\
G_{i}(s)=\frac{1}{1+\tau_{i} s}
\end{array}
$$

The outer voltage control block is shown in Fig. 3 based on Eqns. (9), (10), (11), and (12) where $K_{v d}$ and $K_{v q}$ are the PI-compensators in DQ reference frame.
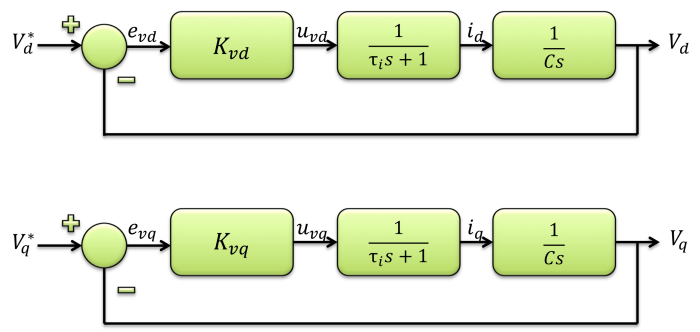

Fig. 3. Simplified control block diagram of the outer voltage loop.

\section{B. Controller Design}

Designing V/F controller basically depends on determining the optimal operating structure of the system and regulating the compensators. These elements have to accomplish stability, fast response and disturbance rejection. Since all signals are transferred into DQ reference, PI controller is a sufficient compensator to provide zero steady state error. The open-loop transfer function of the inner current controller is obtained from Fig. 2 and illustrated as:

$$
\begin{aligned}
l_{i}(s) & =K_{i}(s) P_{i}(s) \\
& =\left(k_{i p}+\frac{k_{i i}}{s}\right) \frac{1}{L s+R}
\end{aligned}
$$

where $K_{i}(s)$ and $P_{i}(s)$ are the transfer functions of the controller's compensator and plant.

The order of the closed-loop transfer function of the current is less than 3 which is recommended to use "Modulus Optimum" technique [11]. This method is suitable to tune the parameters of the inner current compensator because of its simplicity and accuracy.

The open-loop transfer function of the current is obtained from Fig. 3 as follows:

$$
\begin{aligned}
l_{i} & =K_{i p}\left(\frac{s+\frac{K_{i i}}{K_{i p}}}{s}\right) \frac{1}{L\left(s+\frac{R}{L}\right)} \\
& =\frac{K_{p}}{R \tau_{i} s}
\end{aligned}
$$

where $\tau_{i}=\frac{L}{R}$ is the desired closed-loop time constant. The dominate pole of the plant can be canceled by adjusting the 
zero of PI-compensator. By letting $K_{i p}=\frac{L}{\tau_{i}}$ and $K_{i i}=\frac{R}{\tau_{i}}$, the closed loop response can achieve the designing requirements. The open and closed loop transfer functions of the inner current will be formed as:

$$
\begin{aligned}
G_{i_{o l}} & =\frac{K_{i p}}{L s} \\
G_{i_{c l}} & =\frac{K_{i p}}{L s+K_{i p}}=\frac{1}{\tau_{i} s+1}
\end{aligned}
$$

Tuning the compensator depends on the desired requirements of system in both time and frequency domains. One of the important key in tuning the system is to design a closed-loop bandwidth. The bandwidth of the inner current loop should be limited to be at least 10 times lower than the switching frequency to avoid interfacing with switching frequency noise. The value of $\tau_{i}$ regulates the desired closedloop bandwidth. The time constant $\tau_{i}$ is selected to be as:

$$
\omega_{\text {switching }}>10 \times \omega_{i}>\omega_{n} .
$$

where $\omega_{\text {switching }}, \omega_{i}$ and $\omega_{n}$ are switching frequency, inner loop frequency and natural frequency of the system respectively.

The desire of tuning the inner controller is to achieve fast response. Beside, the main goal of designing the outer loop is optimum regulation and stability [10], [11]. The outer voltage loop in Fig. 3 shows the open loop transfer functions. It can be concluded that the system has two poles in the origin regarding which "Modulus Optimum" can not be applied to tune the controller. Instead, "Symmetrical Optimum" method is used to provide more stability to the system by providing more delays in certain frequency [11].

The open loop transfer function of the voltage controller is given as:

$$
\begin{aligned}
l_{v}(s) & =K_{v}(s) G_{i c l}(s) P_{v}(s) \\
& =\left(k_{v p}+\frac{k_{v i}}{s}\right)\left(\frac{1}{\tau_{i} s+1}\right)\left(\frac{1}{C s}\right)
\end{aligned}
$$

where $C_{v}(s), G_{i c l}(s)$ and $P_{v}(s)$ are the transfer functions of outer loop compensator, inner closed-loop current and outer voltage plant respectively. The detailed equations for tuning the outer voltage loop are as follows:

$$
\begin{aligned}
\omega_{\text {cutoff }} & =\frac{1}{\sqrt{T_{s} \tau_{i}}} \\
\Phi_{\max } & =\sin ^{-1}\left(\frac{T_{s}-\tau_{i}}{T_{s}+\tau_{i}}\right) \\
K_{v p} & =C \omega_{\text {cutoff }}
\end{aligned}
$$

where $\omega_{\text {cutoff }}, T_{s}$ and $\Phi_{\max }$ are outer-loop cutoff frequency, compensator time constant and maximum open-loop phase margin respectively. Regulating the load voltage is achieved by controlling of the magnitude of voltage components in DQ reference frame that is presented as $V_{s}=\sqrt{v_{s d}^{2}+v_{s q}^{2}}$ while the frequency is provided by Voltage-Controlled Oscillator (VCO). The selected parameters and bandwidth of the designed inner current and outer voltage loops are given in Table I. The overall V/F control algorithm of VSC based autonomous mode is shown in Fig. 4 .
TABLE I

PARAMETERS OF THE CURRENT AND VOLTAGE CONTROLLERS.

\begin{tabular}{|c|lc|c|ll|}
\hline$\omega_{n}$ & 377 & $\mathrm{rad} / \mathrm{sec}$ & $K_{i p}$ & 4.28 & $\Omega$ \\
\hline$\omega_{\text {switching }}$ & $19000 \mathrm{rad} / \mathrm{sec}$ & $K_{i i}$ & 2000 & $\Omega / \mathrm{sec}$ \\
\hline$\omega_{i}$ & $2000 \mathrm{rad} / \mathrm{sec}$ & $K_{v p}$ & 0.6699 & $\Omega^{-1}$ \\
\hline$\omega_{v}$ & 1000 & $\mathrm{rad} / \mathrm{sec}$ & $T_{v}$ & 4.5 & $\mathrm{msec}$ \\
\hline$\omega_{\text {cutoff }}$ & $670 \mathrm{rad} / \mathrm{sec}$ & $\Phi_{\max }$ & $53^{\circ}$ & \\
\hline
\end{tabular}

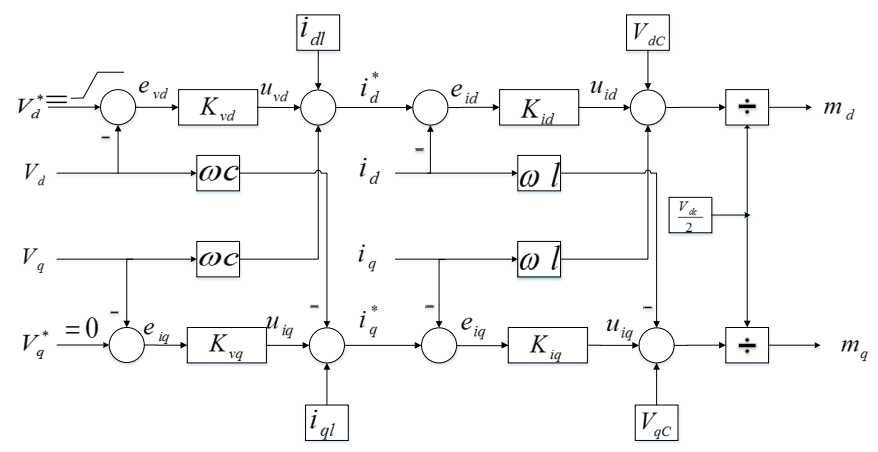

Fig. 4. VF control algorithm for VSC at autonomous mode.

\section{INDUCTION MOTOR}

\section{A. Issues of Starting Motor}

Starting of an induction motor from standstill at full rated voltage consumes high starting current. This high current is calculated from the relation between stator voltage and current as:

$$
\begin{aligned}
I_{\text {stator }} & =\frac{V_{\text {stator }}}{Z_{\text {thevenin }}}=I_{\text {stator }}+I_{\text {rotor }} \\
Z_{\text {stator }} & =R_{\text {stator }}+j X_{\text {stator }}+X_{m} / /\left(\frac{R_{\text {rotor }}}{\text { slip }}+j X_{\text {rotor }}\right)
\end{aligned}
$$

It can be seen from Eqn. (26) that the high starting current depends on to the value of the rotor resistance. At IM's standstill, the slip equals 1 and the rotor resistance has low value. Therefore, the rotor current is high as well as the stator excitation current. These currents are almost five to eight times the rated current at steady state [12].

In order to investigate the impact of starting current on the microgrid, the relationship between the voltage source and the voltage at $\mathrm{PCC}$ is given as:

$$
I_{\text {line }}=\frac{V_{s}-V_{\mathrm{pcc}}}{Z_{\text {line }}}
$$

In case of a strong system where the line impedance is low, the starting current would not affect the voltage at PCC. However, if the line impedance is high, starting current can negatively impact on the magnitude of the load voltage. This negative impact may produce voltage dip on the system.

According to [13], the AC system is classified as a weak system if the Short Circuit Ratio (SCR) is less than $2 \mathrm{pu}$. Consequently, If the IM load is connected to the weak system, the voltage at PCC is very sensitive to any changes in the load such as starting current of IM. 


\section{B. Proposed Method}

The high starting current in Eqn. (26) can not be avoided when the IM is connected to the full rated voltage. A possible solution to lower the starting current is to decrease the applied stator voltage. It is proposed to increase the stator voltage from zero up to full rated voltage gradually. Therefore, voltage dip can be avoided in case of weak system as well as limiting the starting current.

Large industrial motor is examined in this paper to investigate its impact on the system. The parameters of the motor are obtained from type-2 motor [14]. The starting current and consumed reactive power during IM startup when Direct-OnLine (DOL) method is used are shown in Fig. 5. It is observed that the starting current and reactive power consume almost 6 pu and 3 pu respectively.

Since the VSC controls the voltage and frequency of the system, fixing the frequency and applying ramped stator voltage leads to gradually increasing currents. This method can limit of the maximum starting current as well as avoiding voltage dip on a weak system.

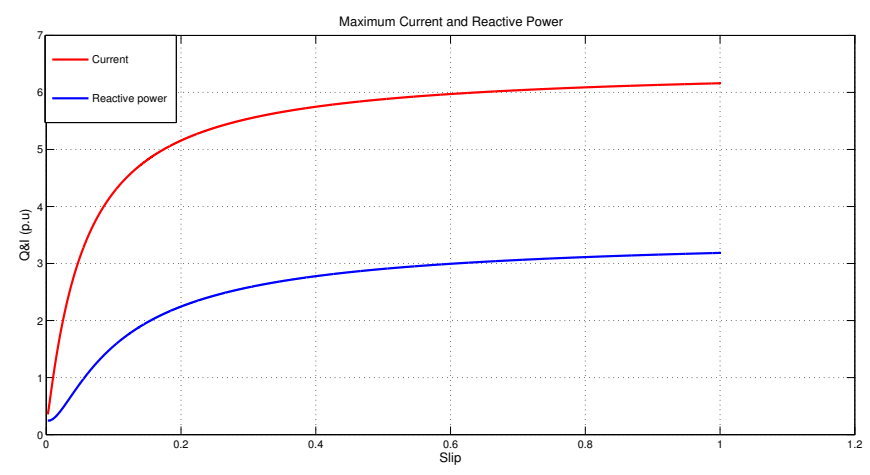

Fig. 5. Starting current and reactive power characteristic using DOL method.

\section{Simulation Results OF THE SYSTEM}

Blackstart of IM will be simulated in PSCAD/EMTDC. $\mathrm{V} / \mathrm{F}$ controller of VSC based autonomous mode is applied and examined. The Direct-On-Line (DOL) method is first applied when IM load is connected to a weak system. A solution of blackstart is then evaluated by using soft start technique. Different voltage ramp cases are applied to decrease the maximum starting current. The overall scheme of the microgrid is shown in Fig. 6 and the rated parameters of the system are presented in Table II.

\section{A. Case Study}

Starting of IM has a negative impact on the autonomous microgrid. Voltage dip may occur when the IM load is connected to a weak system. For example, the simulated microgrid in Fig. 6 has SCR equals 2 pu which indicates that the system is weak. In order to validate the proposed method, the microgrid is first examined when the IM is directly connected to a weak system. At 1 second, the load breaker is closed and the motor receives a full rated voltage. The motor parameters and the

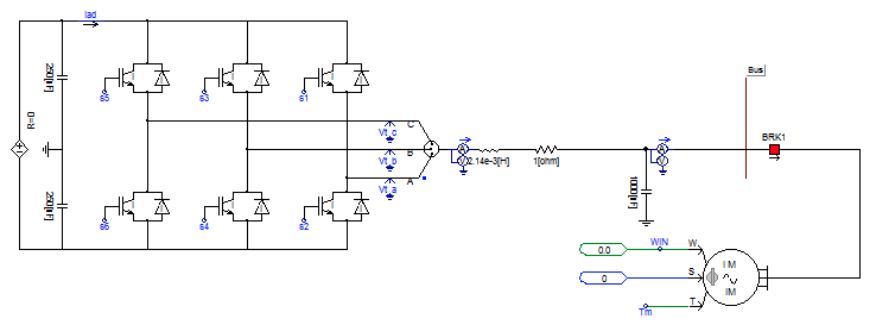

Fig. 6. Overall view of a microgrid using PSCAD simulation.

TABLE II

PARAMETERS OF MiCROGRID.

\begin{tabular}{|c|c|c|c|}
\hline Microgrid Components & Values & Induction Motor & Values \\
\hline $\mathrm{L}$ & $2.14 \mathrm{mH}$ & $P_{I M}$ & HP \\
\hline $\mathrm{C}$ & $100 \mathrm{uF}$ & $V_{I M}$ & 220 \\
\hline $\mathrm{R}$ & $\Omega$ & Slip & 0.028 \\
\hline$\overline{V_{\mathrm{dc}}}$ & $500 \mathrm{~V}$ & Pole & 4 \\
\hline$C_{\mathrm{dc}-\text { link }}$ & $250 \mathrm{uF}$ & $R_{\text {stator }}$ & $0.1062 \Omega$ \\
\hline$P_{\mathrm{dc}}$ & $30 \mathrm{~kW}$ & $\overline{R_{\text {rotor }}}$ & $0.0764 \Omega$ \\
\hline$F_{\text {Switching }}$ & $3000 \mathrm{~Hz}$ & $X_{\text {stator }}$ & $0.2145 \Omega$ \\
\hline$V_{L L}$ & $220 \mathrm{~V}$ & $X_{\text {rotor }}$ & $0.2145 \Omega$ \\
\hline & & $X_{m}$ & $5.834 \Omega$ \\
\hline
\end{tabular}

system's behavior is shown in Fig. 7 when DOL method is applied.

It can be recognized that the starting current is very high which is almost 7 times the rated current. This high current produces voltage dip on a weak system. According to IEEE, the standard voltage dip should not be lower than $80 \%$ of the rated voltage when the motor is directly connected to the system. Since the IM load is connected to weak system, voltage dip occurs which is about $70 \%$ lower than the recommended voltage as shown in Fig. 7.

The V/F controller based on soft start is examined with a voltage ramp response. The IM is connected to the microgrid and the behavior of the IM is shown in Fig 8. It can be seen that the torque and speed of the IM are smoothly increased which provides more efficiency to the torque. The stator voltage ramps smoothly until it reached the rated value of IM as shown in Fig. 8. It is observed that the controller can limit the high starting current of IM.

Different voltage ramp cases are applied to limit the maximum starting current as given in Table III. The final voltage magnitude is set at rated phase voltage while the ramping rate is varied to limit the starting current. The trade off between the maximum starting current and the transient time needs to be considered. For instance, longer transient time leads to a decreasing the maximum starting current. In this case, the maximum starting current can be lowered less than $80 \%$ of the maximum starting current in the DOL case should the stator voltage be ramped at a of $1 \mathrm{pu} / 19$ seconds.

\section{CONCLUSION}

In this paper, blackstart problem of IM when connecting to a weak microgrid is presented. VSC is used to control the voltage and frequency in an autonomous microgrid. The paper provides a method to control blackstart of IM using VSC when the system is weak. Designing and tuning V/F 

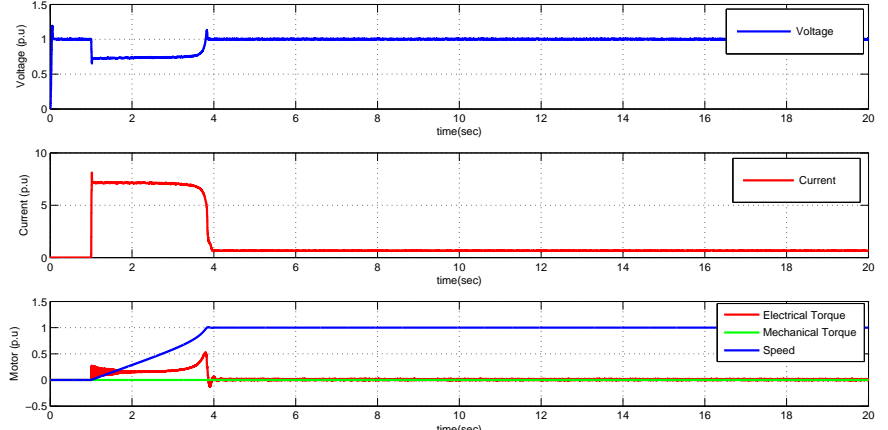

Fig. 7. Microgrid behavior using DOL. Top figure is the voltage at PCC. Middle figure is the Line current. Bottom figure is the torques and speed of the IM.

TABLE III

DIFFERENT CASES OF VOLTAGE RAMP

\begin{tabular}{|c|l|l|l|l|}
\hline Voltage Ramp & $T_{\text {settling }}$ & $I_{\max }$ & $I_{\max } \%$ & $T_{\max }$ \\
\hline 1 & $5 \mathrm{sec}$ & $7.0 \mathrm{p} . \mathrm{u}$ & $100 \%$ & $0.50 \mathrm{p} . \mathrm{u}$ \\
\hline 2 & $9 \mathrm{sec}$ & $6.7 \mathrm{p} . \mathrm{u}$ & $95 \%$ & $0.45 \mathrm{p} . \mathrm{u}$ \\
\hline 3 & $13 \mathrm{sec}$ & $6.1 \mathrm{p} . \mathrm{u}$ & $87 \%$ & $0.35 \mathrm{p} . \mathrm{u}$ \\
\hline 4 & $19 \mathrm{sec}$ & $5.5 \mathrm{p} . \mathrm{u}$ & $78 \%$ & $0.25 \mathrm{p} . \mathrm{u}$ \\
\hline
\end{tabular}

controller of VSC are also provided. Voltage dip is occurred in weak systems and soft start method can solve this issue. This technique can limit the starting current as well.

Simulation results by PSCAD confirm the effectiveness of the soft start method to mitigate the blackstart issues related to high starting current and reactive power. It can be seen clearly that the controller can decrease the maximum starting current.

\section{REFERENCES}

[1] J. Carrasco, L. Franquelo, J. Bialasiewicz, E. Galvan, R. Guisado, M. Prats, J. Leon, and N. Moreno-Alfonso, "Power-electronic systems for the grid integration of renewable energy sources: A survey," Industrial Electronics, IEEE Transactions on, vol. 53, no. 4, pp. 1002-1016, June 2006.

[2] N. Flourentzou, V. Agelidis, and G. Demetriades, "Vsc-based hvdc power transmission systems: An overview," Power Electronics, IEEE Transactions on, vol. 24, no. 3, pp. 592-602, March 2009.

[3] R. Lasseter, "Microgrids," in Power Engineering Society Winter Meeting, 2002. IEEE, vol. 1, 2002, pp. 305-308 vol.1.

[4] "Ieee recommended practice for industrial and commercial power systems analysis (brown book)," IEEE Std 399-1997, pp. 1-488, Aug 1998.

[5] J. Larabee, B. Pellegrino, and B. Flick, "Induction motor starting methods and issues," in Petroleum and Chemical Industry Conference, 2005. Industry Applications Society 52nd Annual, Sept 2005, pp. 217222.

[6] A. Williams and M. Griffith, "Evaluating the effects of motor starting on industrial and commercial power systems," Industry Applications, IEEE Transactions on, vol. IA-14, no. 4, pp. 292-305, July 1978.

[7] J. Rodriguez, E. Pena, P. Larrea, H. Duarte, and A. Rodriguez, "Dynamic performance of a statcom under grid disturbances for two different linear controllers," in IECON 2012 - 38th Annual Conference on IEEE Industrial Electronics Society, Oct 2012, pp. 356-361.

[8] L. Zhang, L. Harnefors, and H.-P. Nee, "Power-synchronization control of grid-connected voltage-source converters," Power Systems, IEEE Transactions on, vol. 25, no. 2, pp. 809-820, May 2010.

[9] M. Kazmierkowski and L. Malesani, "Current control techniques for three-phase voltage-source pwm converters: a survey," Industrial Electronics, IEEE Transactions on, vol. 45, no. 5, pp. 691-703, Oct 1998.

[10] A. Yazdani and R. Iravani, Voltage-sourced converters in power systems: modeling, control, and applications. John Wiley \& Sons, 2010.
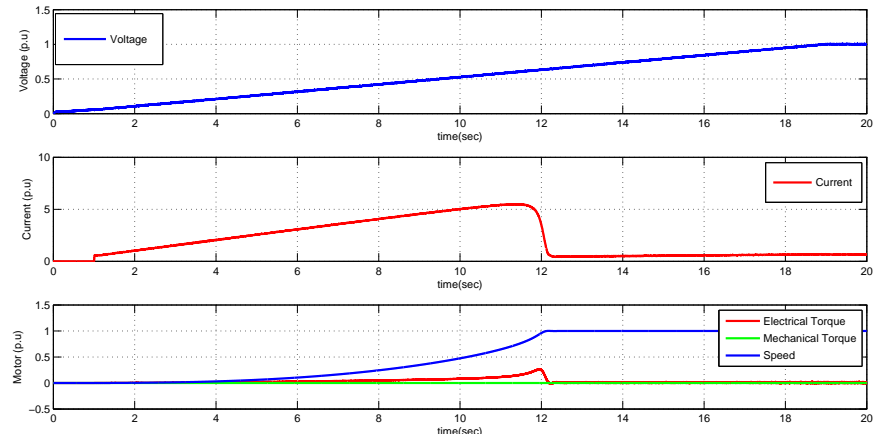

Fig. 8. Microgrid behavior using soft start. Top figure is the voltage at PCC. Middle figure is the line current. Bottom figure is the torques and speed of the IM.

[11] C. Bajracharya, M. Molinas, J. A. Suul, T. M. Undeland et al., "Understanding of tuning techniques of converter controllers for vsc-hvdc," in Nordic Workshop on Power and Industrial Electronics (NORPIE/2008), June 9-11, 2008, Espoo, Finland. Helsinki University of Technology, 2008.

[12] P. C. Sen, Principles of electric machines and power electronics. John Wiley \& Sons, 2007.

[13] "Ieee guide for planning dc links terminating at ac locations having low short-circuit capacities," IEEE Std 1204-1997, pp. i-, 1997.

[14] W. Price, C. Taylor, and G. Rogers, "Standard load models for power flow and dynamic performance simulation," IEEE Transactions on power systems, vol. 10, no. CONF-940702-, 1995. 